\title{
Exploring Pre-service Teachers' Perception of Interactional Activities in Lesson Planning
}

\author{
Justina, A. Njika ${ }^{1}$ \\ ${ }^{1}$ Associate professor of Applied Linguistics, Higher Teacher Training College (ENS) Yaounde, Cameroon \\ Correspondence: Justina, A. Njika, Associate professor of Applied Linguistics, Higher Teacher Training College \\ (ENS) Yaounde, Cameroon
}

Received: February 6, 2020

Accepted: February 28, 2020

Online Published: February 29, 2020

doi: 10.5539/elt.v13n3p92

URL: https://doi.org/10.5539/elt.v13n3p92

\begin{abstract}
With the plethoric number of students in Cameroonian classrooms today, there is a common cry from teachers about the impracticability of creating interactional language lessons in the English as a foreign language (EFL) classroom. The implication of this is that, if interactional lessons have been identified as cardinal in the process of language learning, our learners are not or are less likely to be learning English as a foreign language. This paper holds that no teacher will be able to create interactive lessons if they do not fully understand what it is and how it works. The paper therefore investigates student teachers' perception of interaction on a less theoretical stance to posit that their readiness to teach is governed by their perception of the concept of interaction and an understanding of how it works. Data were collected from two batches of 30 pre-students students from the Department of English at ENS Yaounde in 2018 and 2019. Upon completion of three semesters that qualify them to do practicum, they were asked to submit language lessons meant for interactive classrooms. The lessons were coded identifying trends related to interactive activities and later classified. Evidence from the data demonstrates significant recourse to previous learning culture of top-bottom lessons and high incidences of question-and-answer as a dominant pattern of interaction. In keeping with this, the paper questions the training approaches and argues that the inability of pre-service teachers to demonstrate practical understanding of classroom interaction is counterproductive to what potentially holds as language learning and that modules of training which allow teachers to seek patterns would be more productive than those which train them on classroom interaction.
\end{abstract}

Keywords: ELT, classroom interaction, lesson planning, pre-service teachers, perception, learners

\section{Introduction}

Modern trends in ELT suggest that learning a foreign language is more of a matter of interaction than a situation of teacher-directed learning (Gass, 2005, Chavez, 2009) and that creating interactive activities in the language classroom is primordial to language development. There have, however, been some arguments as to the possibilities of creating interactive lessons in large classes especially in low resourced contexts. Whether or not this is true, it seems to be more important stating that the teachers' knowledge of interaction plays a greater role on decisions related to creating interactive lessons. To be clearer, a teacher's ability to create interactive activities is based on a sound mastery of interaction and an understanding of the context in which he/she finds himself. In essence, there are lots of unpredictable situations in the classroom, most of which result from interaction. Anderson (2015) that teachers in training are not well prepared for handling unpredictable events and may not make the most opportunities for real learning within their lessons. Such unpredictable situations require creativity constructed in the teacher through both training procedures and insights developed from learning resources. In Cameroon, the myriad of factors that combine to construct a teacher from, selection, preparation to insertion tend to exert a greater influence on the pre-service teachers than the training process itself. It is complicated to assert at this early stage whether or not the problem could be mismatch between the training package and the experience the trainees bring into the training colleges .The purpose of this paper is to explore pre-service teachers' perception of classroom interactive activities prior to practicum to be able to assess their potentials of generating authentic language use in the classroom. Interactive lessons here is understood to be the kind of activities teachers create in the language classrooms to increase learners' participation in the lessons in the entire learning process. This is necessary in understanding the effect of training on their knowledge of classroom practices in view of making concise statements of how productive training has been or ought to be, including how they later develop as 
in-service teachers informed by the nature of their jobs. There have been different accounts of the relationship between interaction and leaners' participation in the classroom and the types of interaction that yields better benefits to learning. It is not yet clear in the literature whether teachers' ability to create interactive lessons relates more with their understanding of their learners or is the outcome of training. This paper attempts to clarify this.

\section{Interactive Lessons and Input}

It is necessary shedding some light on what really counts as interactive lessons and how they mediate with content-input- and outcomes. The language content a leaners is exposed to has to be processed and the notion of processing doesn't simply mean presenting the target language point, explain, allowing learners to practice and then expecting positive outcomes. It more or less depends on the nature and manner of presentation and the rationale learners find learning the language point. It seems more plausible correlating the rationale with the nature of activities initiated in the classroom than tallying it with the structure. The reason being that, the rationale for learning a language point mostly establishes the link between real occasion for using the target language point and activities generated by the teacher in the language lesson. This is where the idea of input frequency and processing has relevance. Four main issues identified about input are that input, first, is the language data (abstract), which is either comprehensible or incomprehensible although there are questions as to what should be considered (in) comprehensible input. Second, Input is also valued in terms of frequency, thirdly, it is equally valued as a carrier of content or expressing some environmental concept. Lastly and most importantly, it is the primary data which the learner is exposed to for subsequent language use. The idea of use has a major orientation in the way learners engage in activities and how the activities reflect their ordinary-day experience of the learners. As Gass (1994) argues, the formulation of any theory in SLA should hold the outcome of learning as a replica of the learners' environmental realities and not as borne only out of general psychological tendencies. For leaners to find interest in interactive activities, such activities carrying the input should therefore take care of the four points explained above. These play significant roles in how learners attend to and process the input. A consensus reached by many scholars (Van Patten 1994, Ayoun 2001, Long 2000 for example) is that the best way to get learners attend to input is to alter it in a way that encourages them to attend to target items for meaning. In this way, the activities induced are intended to change the learners' negative processing strategies and focus their attention on the form-meaning connection such that they discover why certain structures they are working on might be learned when they make sense (Garcia 2008).

That is, input must be comprehensible before it is attended to. We should, at this point, leave open the possibility that learners can attend to input without any meaning-to- form connection by simply following the 'aesthetics' of the grammatical rule. This is usually the effect of explicit grammar instruction, which Van Patten and Cadierno (1993) criticise as being mechanical. Although this is actually mechanical, foreign language learners (especially adults) may easily benefit from this type of exposure if the rule is well explained (Shawood Smith 1981: 159-160, Brindley 1987: 190-191). The effects in this case, remain highly abstract and the teaching outcome may not form any actual language base in the learner. When input makes sense to the learners, attention to meaning is likely to proceed from it, but it will be easily processed than when learners get only the form. In a context where learners are exposed to several codes out of the classroom (like in Cameroon), input from a particular language needs to be frequent, extraordinary and should make a difference from the sub-standard structures the learner is primarily exposed to in the natural environment.

The frequency approach to input is believed to be equally crucial in determining how much attention is paid to input because of its foundations on usage-based and not necessarily on processing. With regard to invaluable details related to the frequency effects as identified by Nakamura (2008), it is held that the repetition of a particular item has three roles: it strengthens its representation in memory thus leading to resistance to change (known otherwise as the conserving effects), it makes it a chunk without analysis or decomposition of its internal structure (known as autonomy) and has an effect on phonetic reduction (the reducing effects). It is worth noting that repeating the input may also take the form of different engaging classroom activities which learners have to be exposed to. Another approach to input and its processability as suggested by Nakamura is derived from studies conducted by Childers and Tomasello (2001) in which they note that input consistency as well as input variability (in nouns in subject and object slots for example) within construction promotes awareness of the whole constructional frame. Within the token frequency and usage based views of input, frequency is held to be responsible for memory strengths while consistency is believed to be accountable for construction. This generally occurs in the classroom in patterns that are unaccounted for in lesson plans. In lesson planning, (Mass, 2017) argues for the need to include enough time and flexibility for learning to occur in unplanned or unanticipated ways. Examining trainees' lessons plans is cardinal, especially as they are necessary components for the assessment of teaching during initial training, advanced qualifications, quality assurance inspections, and 
in-service teacher development (Anderson, 2015), although they have received very limited attention in ELT discourse. Drawing from Anderson (2015) and Mass (20107), the need to allow space for the natural development of interaction in the classroom renders language lessons natural and this largely depends on the way trainees appreciate learners' input or feedback and understand the value of interaction.

\section{Interaction}

The learner, in the learning process is usually found to be involved in an exchange between himself and (an) other people but his success in learning is dependent on a number of variables. Learners' continuous commitment in negotiating meaning, expressing their opinions and reacting to others' exigencies (using the target language) in either free or restricted, but purposeful situations owes much to interaction. Malamah (1987: 7) sees interaction as acting reciprocally, acting upon each other. This supposes that in a situation of interaction, there must be interlocutors, there must be an exchange, and there must be negotiation, there must be input. Interaction which is based on naturally occurring situations is greatly responsible for learning and is generally conditioned by the type of learning activities selected by the teacher. Comprehensible input in natural interactions may lead "to the need to express meanings which may stretch interlanguage" (Skehan 1998: 104). Malamah sees classroom interaction as a situation whereby, the teacher acts upon the class, but the class' reaction subsequently modifies the teacher's next action and so on. The class' response to him/her becomes another action provoking a reaction in the teacher, which influences his subsequent action. This explains why it is believed that in interaction, there is a constant pattern of mutual influence and adjustment between the encoder and the decoder and changing roles in which the addresser at one point becomes the addressee at another point and vice versa.

In carrying out the mutual exchange, the interactants must feel that there is a purpose for undertaking such an endeavour and that the purpose has an impact on each other. If not, interaction, especially on the part of the learner will not be guided by free will. This is where the teachers' ingenuity of creating interactive activities chains with his/her understanding of the learners, what they are capable of (not) doing and the conditions available for it to work effectively. Every interaction situation, it is argued, has the potential for co-operation or conflict. "How the situation actually develops depends on the attitudes and intentions of the people involved, and on their interpretations of each other's attitudes and intentions". This has a tremendous influence on the progress learners make in the classroom. If the teacher is looked upon by his learners as coming from an 'inferior' culture, the learners may tend to associate such inferiority with the target language. Equally, if the teacher comes from a culture that has strict respect for human values and is teaching learners with a 'rowdy' culture, interaction in the classroom may generate a conflict between the two cultures.

Attitudes and intentions in the classroom are mutually constructed to accommodate participants in learning events with all participants conscious of their common purpose, a critical role any activity related to classroom interaction Another characteristic role of interaction is that, in a situation of interaction, learners adjust their output, which later serves as input to other learners (Hedge, 2000). This implies that activities intended to create opportunities for learners to interact in the classrooms must take into consideration the mutuality of effect as well as the relevance. Classroom interaction follows Initiation (I), Response (R), Feedback (F)-(IRF) from a behaviourist perpective, and draws from Flander's Interaction Analysis Categories (FIAC), grouped under teacher talk and student talk. (Malamah, 1987). The understanding of both teacher talk and student talk in the language classroom could be an effective starting point for teachers to monitor how effective their activities in the language classrooms are and could as well be an important observation technique in describing classroom types just as classroom language itself. It is argued that when both partities in an interactional event observe Grice's maxims with a reciprocal agenda, learning tends to be faster. Here language is constructed and negotiated to the benefit of all parties (Wells, 1981) qtd in Ellis (1984: 97). In multilingual classrooms (as is the case in Cameroon, for example), interaction is believed to be useful in classes that are highly composed of non-English-speaking learners with a teacher-centred approach and in open organizational classes that have both English-speaking and non-English-speaking children. However, a few circumstances during which interaction may not be profitable are noted to be related to classes with open organization which have a high proportion of non-English-speaking children and in classes that are teacher-centred with mixed English-speaking and non-English speaking children (Filmore, 1982). One of such aims of interaction in the classroom is to reduce learners' dependence on a teacher and ensure learners' absolute involvement in the learning process. As to the type of interaction that best facilitates the rate of learning, a well-intended blend of classroom activities, lesson objectives, language points, teacher's language awareness, managerial techniques and the context of learning is necessary. All of these have to be blended so as to give classroom interaction the dimension it deserves at each point in time. Filmore's claims however need more insights as learners with different goals, different attitudes, and different scales of motivation may require varying classroom types. Therefore, the learners confronted in each context determine what kind of interaction is necessary 
for them. Whatever the situation, all classrooms demonstrate a high dependency on interaction as it (interaction) generates the input necessary for learning though with varying degrees.

\subsection{Background to the Study}

This study involves two groups of pre-service teachers trained in ENS Yaounde for three semesters each, who were all ready to start practicum. Apart from other ELT course they had taken in both the fourth and fifth years of their study in ENS Yaounde, they particularly had not less than 112 hours of direct instruction on classroom interaction and Discourse Analysis during which they read articles, book chapters, case studies and made presentations on DA and CI in not less than twenty sessions in all. The presentations were followed by general feedback from both the researcher and peers. One of the purposes for allowing students carry out presentations on these topics was to allow them to make judgements on the appropriateness of the materials they read to Cameroonian classrooms which they were familiar with and to simulate instances of interaction in the local contexts. They were assigned to produce lesson plans for EFL low proficiency learners taking into consideration instances of interaction in the lesson and were given two weeks to submit the task. We decided to ask them to do lesson plans because it entailed application of knowledge they had gained from reading materials and classroom discussions. In all, 40 lesson plans worthy of analysis were successfully tuned in from the two groups.

\subsection{Methods}

Excerpts of interaction were extracted from the 40 lesson plans and coded based on the possibilities of the different kinds of interaction that would possibly ensure where the lesson had to be delivered. We were, however, aware of the possibilities of adjustments during lesson delivery and so the interest in the study was steered more towards unveiling understanding of what really counts as interactional activities in the lesson. It is important to indicate here that, in situations where the focus of lesson plan analysis is on perception, lesson delivery may not be a very useful tool for analysis. This explains why we focused more on planning, especially as planning goes more with perception and conception. Understanding students' perspectives is critical as students with different social backgrounds tend to perceive and participate in classroom interactions in different ways (Vogler and Prediger, 2017).The aspects of the lessons that were given sufficient attention were teacher's activities and learners' activities. Focus on these rubrics was driven by the fact that that a logical reading of teachers and students' activities would produce an understanding of how the pre-service teachers encoded and captured the whole discourse on interaction. For easy analysis, each lesson plan was scanned for interactional activities created by the pre-service teachers and juxtaposed with its corresponding students' activities. Instances that did not show evidence of interactional activities were not considered, given that our interest was to capture participants' perception of interaction vis-à-vis their context. A second reading was done to classify instances of interaction with common patterns. In all the 40 lessons 73 instances of interaction were identified and coded and distributed as follows: $38(52.1 \%)$ out of the 73 instances of interaction associated with the teachers' previous learning experiences while $31(42.1 \%)$ of the instances of interaction demonstrating high episodes of question-to-answer type of interaction. An insignificant (5.5\%) of instances of distribution of horizontal exchange of ideas in-between learners was traced.

\subsection{Recourse to Previous Learning Experiences}

The dominant experiences identified in the lessons could be associated with the pre-service teachers' previous learning experiences. The learning culture in EFL classrooms in Cameroon is characteristically that of power held by the teacher and released only when he/she feels safe. Proof of this is the flooded nature of the teachers' activity rubric with statements that reveal a mono-directional pattern of questioning in which the role of the teacher was essentially that of the addressee. See the following samples written exactly as were found in the lesson plans: 
Table 1. Samples of language related to previous learning experiences

\begin{tabular}{|c|c|c|}
\hline Coding & Teachers' Activities & Students' Activities \\
\hline EP 1 & $\begin{array}{l}\text { Teacher instructs leaners to go in front of the } \\
\text { class and give examples of nouns }\end{array}$ & $\begin{array}{l}\text { The other learners repeat what the learner is saying } \\
\text { and in case of any wrong answer, they correct the } \\
\text { learners }\end{array}$ \\
\hline EP 2 & $\begin{array}{l}\text { Teacher asks learners to make simple } \\
\text { sentences with the items listed and read in } \\
\text { front of the class }\end{array}$ & $\begin{array}{l}\text { Learners make simple sentences together and } \\
\text { presenter takes it to the front of the class and } \\
\text { presents them }\end{array}$ \\
\hline EP 3 & $\begin{array}{l}\text { Teacher asks individual learners to come to } \\
\text { the front of the class or stand up and identify } \\
\text { the pictures of the items }\end{array}$ & $\begin{array}{l}\text { Learners listen and watch attentively as they are } \\
\text { being called up one after the other to identify the } \\
\text { items by the teacher }\end{array}$ \\
\hline EP 4 & $\begin{array}{l}\text { Teacher gives sentences for students to } \\
\text { complete using concrete nouns }\end{array}$ & $\begin{array}{l}\text { Learners fill in the blanks by copying in their } \\
\text { books }\end{array}$ \\
\hline EP 5 & $\begin{array}{c}\text { Teacher asks students to draw a list of food } \\
\text { items }\end{array}$ & Students draw a list of foods \\
\hline EP 6 & $\begin{array}{l}\text { Teacher asks learners to say what they will } \\
\text { say if they got to a shopping place to buy food } \\
\text { stuffs }\end{array}$ & $\begin{array}{l}\text { Learners express themselves dwelling on the } \\
\text { manner of approach. }\end{array}$ \\
\hline
\end{tabular}

The nature of teacher intervention in the contexts, from the table above, is that of the boss giving instructions that have to be executed with limited opportunities for learners to construct sense out of what is expected of them. There is no evidence of learners not executing the instruction and whatever these instructions mean are fairly interpreted by the teacher- and not by the learners- as relevant, irrespective of whether learners have rationale for executing the instructions or not. A more characteristic feature of the episodes is related to the structural dimension of language with no meaning-form circumstances aimed at driving the learners into activity. Learners draw a list of food items is carried out as instructed by the teacher and not in function of how they may naturally want to use the list in subsequent activities. In terms of roles and responsibilities, the teacher remains the addressor and mutuality of interaction is not shared. This defeats the whole understanding of a language classroom as a discourse community where roles and responsibilities are shared with a common purpose to build a community of learners. Notice that learning opportunities are established when students can actively participate in the negotiation of meanings and when the teacher offers them space in which to express their ideas and support their realizations (Volger and Pridiger, 2017). This must not be confused with the instance in EP1 wherein the teacher instructs leaners to go in front of the class and give examples of noun, and the other learners repeat what the learner is saying and in case of any wrong answer, they correct the learners. There is no construction of knowledge in this instance and the teacher remains the boss steering the understanding of dry grammar that suits his objectives with no real life situation that reflects language use.

\subsection{Question-and-Answer Sessions}

Another feature of the patterns of interaction was the question-and-answer episodes during which teachers asked questions and learners provided answers considered by the student teachers to mean interaction. We do not intend to undermine teacher-led interaction. The situation demonstrated here is completely different from what actually counts as teacher led interaction. The reason for which the questions and answer sessions tend to be different from interaction is that learners act upon the production of the teacher and the teacher confirms or refutes and then moves into another activity with no corresponding reciprocity to construct meaning. No interest in working up the learners to realise a common achievement was established by any of the instances noted. Consider the following sentences: 
Table 2. samples of Question-and-answer episodes

\begin{tabular}{|c|c|c|}
\hline Coding & Teachers'Activities & Students' Activities \\
\hline EP 7 & $\begin{array}{l}\text { Teacher will ask students what they will buy } \\
\text { for Christmas and places they will visit }\end{array}$ & $\begin{array}{l}\text { Students will respond to teacher's questions. E.g, I } \\
\text { will buy a red gown, I will go to the cinema }\end{array}$ \\
\hline EP8 & $\begin{array}{l}\text { Teacher asks learners why they will visit } \\
\text { particular places and why they will want } \\
\text { particular things }\end{array}$ & $\begin{array}{l}\text { Students will provide answers to the questions } \\
\text { posed by the teacher and write in their exercise } \\
\text { books }\end{array}$ \\
\hline EP 9 & $\begin{array}{c}\text { Teacher asks question, 'what are the different } \\
\text { types of meals you know?' }\end{array}$ & Learners provide answers orally. \\
\hline EP10 & $\begin{array}{l}\text { Teacher asks the learners to list all the } \\
\text { members of their family }\end{array}$ & Learners list all the members of their family. \\
\hline EP11 & $\begin{array}{c}\text { Teacher asks learners, 'have you ever heard } \\
\text { about parts of speech?' }\end{array}$ & Learners provide answers \\
\hline
\end{tabular}

The samples in table 2 reflect the elicitation of information from the learners with no corresponding intention of stretching the learners' interlanguage through follow up questions so that a natural speech event is gradually constructed. Where this is done, learners find the need to act upon the stimulus provided by the teacher and not just simply provide answers to questions. It is through occasions of mutual exchange that more input is elicited and supplied for language to be processed. Input addressed to the learner in the classroom has to be attended to before processing takes place. While some schools of thought stress the importance of input in facilitating attention (Van Patten 1994 for example), others (Swain 1985 for example), think that factors inherent in the learner are what push him to attend to input. She asserts that knowing that one will need to speak makes one more likely to attend to syntax when one is listening. She further suggests that if listeners are aware that it is not enough simply to extract meaning from input, but that they may also need to pay attention to the means by which meanings are expressed in order to use such knowledge as the basis for their own production later, they will be more likely to pay attention to the underlying speech (Swain 1985 cited by Skehan 2001: 80). This renders the question-to answer episodes non-relevant in the multilingual classroom.

\subsection{Horizontal Exchange between Learners}

An insignificant defining feature of interaction as per the lessons analysed was provision for learners to exchange ideas amongst themselves. This is considered insignificant in terms of the instances of occurrences $(5.5 \%)$ in the lesson plans provided by the learners. This was traced in the lesson plans from pair and group work intended in the lessons. The pair and group work were intended to provide occasions for learners to interact amongst themselves. This is ascribed in learner-learner interaction believed to be more productive than teacher-led interaction (Chavez, 2009). Paradoxically, this was the least recurrent feature of interaction identified in the lessons scanned with the samples below.

Table 3. Samples of Horizontal exchange in the lessons

\begin{tabular}{|c|c|c|}
\hline Coding & Teachers' Activities & Students' Activities \\
\hline EP12 & $\begin{array}{l}\text { Teacher puts learners in groups and asks them } \\
\text { to compare their answers with members of the } \\
\text { group }\end{array}$ & $\begin{array}{l}\text { Learners work in groups and exchange ideas and } \\
\text { come up with a conclusion }\end{array}$ \\
\hline EP 13 & $\begin{array}{l}\text { Teacher asks learners in groups to work } \\
\text { together to compare ideas }\end{array}$ & $\begin{array}{c}\text { Learners interact with each other and exchange } \\
\text { opinions }\end{array}$ \\
\hline EP14 & $\begin{array}{l}\text { Teacher asks learners to compare their } \\
\text { answers with their peers }\end{array}$ & Students compare their answers \\
\hline EP15 & $\begin{array}{l}\text { Teacher pairs students in ten groups, six } \\
\text { learners per group and look at what their } \\
\text { fellow peers have written down }\end{array}$ & Learners sit in pairs as positioned by the teacher \\
\hline
\end{tabular}


Group and pair work have been identified as a crucial asset in facilitating interaction in language and especially in a context of large classes (Shamin et al., 2007). How these becomes the least used in the lesson plans scanned gives us pathways for identifying 1) the value pre-service teachers place on their effects in language learning and 2) their utility in the Cameroonian classrooms. It is shared knowledge in foreign language discourse that learners benefit more when they interact with their peers than when they do with their teachers. It is important to mention that pair and group work do not only have the beneficial effect of facilitating learning but enables the teacher to reach out to a wider number of learners at a relatively shorter time. They are thus efficient ways of managing large and over-crowded classrooms. There are more chances that learners will profit from pair and group work as they are not constrained in the process of interaction by both psychological and affective factors. As observed by Jimenez and Mendez (1999: 255), learners feel freer to respond to situations such that they

can learn to predict the location of the next stimulus, not only on the basis of a set of previous locations, but also on the basis of concurrent cues related with the shape of the stimulus [....] and that learning about these cues does not eliminate the effects of grammar learning.

\section{Conclusion}

The features of interaction identified in the lesson plans for this study give us a clue to pre-service teachers' perception of interactional activities in lessons. Deriving from their conception of students and teachers' activities in lesson plans, there is sufficient evidence that the pre-service teachers' perception of interactional activities in language lessons is orientated by their strong presence in the language classrooms under their control in different language related episodes. This presence is translated into a kind of agency in which they take hold of the situations in which learners have to produce language. Given the extensive exposure to current research on interaction at the preparation phase of their training and the degree of autonomy with which they were allowed to explore concepts related to interaction, it is possible to claim previous learning experience as a major strain to their application of new knowledge. The interview type of questions they intended to ask learners during lesson delivery also attests to this. On a more significant note, the fact that their training regarding the concepts made significant use of group work, hoping that gets translated into their working experience raises concerns as to how much is needed to get adults apply knowledge learnt from training. Vogler and Prediger, 2017) report studies claiming teachers' persistent attachment to conceptually unproductive patterns such as the funnel pattern, in which a smooth superficial interaction substitutes for discourse. It seems more sensible to argue that designing training modules that correlate with their previous language learning experience without sacrificing actual training. This raises major concerns regarding the type, effectiveness, and duration of training required for (pre-service) teachers to depart from inherent patterns with regard to interaction. This is more reason for further research in the domain.

\section{References}

Anderson, J. (2015). Affordance, learning opportunities, and the lesson plan pro forma. ELT Journal, 69(3), 228-238, https://doi.org/10.1093/elt/ccv008

Ayoun, D. (2001). The Role of Negative and Positive Feedback in the Second Language Acquisition of Passé Composé and Imparfait. Modern Language Journal, 85, 226-243.https://doi.org/10.1111/0026-7902.00106

Brindley G. (1987). Verb Tenses and TESOL in Nunan, D. (ed.), Applying Second Language Acquisistion Research. National Curriculum Resource Centre: Adult Migrant education Program Australia Research Series, 173-195.

Chavezm M. (2006). Classroom-language use in teacher-led instruction and teachers' self-perceived roles. IRAL, 44(1), 49-107.https://doi.org/10.1515/IRAL.2006.003

Ellis, R. (1984). Classroom Second Language Development. Oxford: Pergamon Press.

Fillmore, W. L (1982). Instructional language as linguistic input: second-language learning in classrooms Wilkinson LC (ed.) Communicating in the Classroom. New York: Academic Press, 283-296.

Garcia, R, (2008). Input Processing and Output Processing in Second Language Acquisition: A Case for the Spanish Subjunctive. In $33^{\text {rd }}$ International Laud Symposium: Cognitive Approaches to Second/Foreign Language Processing: Theory and Pedagogy, pp 409-428.

Gass, S (1994). The Reliability of Second Language Grammaticality Judgements, in Tarone, E, Gass, S. and Cohen, A. (eds.). Research Methodology in Second Language Research. Hillsdale, NJ: Lawrence Erlbaum.

Gass, S (2005). Input and Interaction, in Doughty, C and Long H, M. (eds.), The Handbook of Second Language Acquisition. Oxford,:Blackwell Publishing, 176-200. 
Hedge, T. (2000). Teaching and Learning in the Language Classroom. Oxford: Oxford University Press.

Jesmenez L. \& Mendez C. (1999). Which Attention is Needed for Implicit Learning. Journal of Experimental Psychology: Learning, Memory, and Cognition, 25(1), 236-259. https://doi.org/10.1037/0278-7393.25.1.236

Long, M. (2001). Focus on Form: A Design Feature in Language Teaching Methodology. In Candlin, C and Mercer, N. (eds.). English Language Teaching in its Social Context, 180-190.

Mass, C. (2017). Affordances and learning opportunities in lesson plan templates ELT Research Bites. https://www.eltresearchbites.com/ Accessed Thursday 27 February 2020)

Nakamura, D. (2008). Awareness, input frequency, and construction learning: a replication and extension of Casenhiser and Goldberg (2005) to adult second language acquisition. In: Linguistic LAUD Agency (ed.), 33rd International Symposium: Cognitive Approaches to Second/ Foreign Language Processing: Theory and Pedagogy. Essen: University of Duisburg-Essen, 464-81.

Shamin, F., Negash, N., Chuku , C \& Demewoz, N. (2007). Maximizing Learning in Large Classes. British Council.

Shawood-Smith, M. (1981). Consciousness-Raising and the Second Language Learner. Applied Linguistics, 2(2), 159-69. https://doi.org/10.1093/applin/2.2.159

Skehan, P. (1998). A Cognitive Approach to Language Learning. Oxford: Oxford University Press. https://doi.org/10.1177/003368829802900209

Skehan, P. (2001). Tasks and Language Performance Assessment, in Bygate, M, Skehan, P. and Swain, M. (2001) Researching Pedagogy Tasks: Second Language Learning, Teaching and Testing. London: Peterson Education Limited.

Swain, M. (1985). Communicative Competence: Some Roles of Comprehensible Input and Comprehensible Output in its Development, in Gass, S. and Madden, C. (eds.), Input in Second Language Acquisition. New York: Newbury House pp. 235-256.

Van Patten, B. \& Cadierno, T. (1993) Explicit Instruction and Input Processing. Studies in Second Language Acquisition, 15, 225-43. https://doi.org/10.1017/S0272263100011979

Van Patten, B. (1994). Evaluating the Role of Consciousness in Second Language Acquisition, Terms, Linguistic Features and Research Methodology. In Hulstijn, J. and Schmidt, R. (eds). Consciousness in Second Language Learning. AILA, 11/27-36.

Vogler, A-M \& Prediger, S. (2017). Including students' diverse perspectives on classroom interactions into video-based professional development for teachers. $J$ Math Teacher Educ, 20, 497-513 https://doi.org/10.1007/s10857-017-9382-2

Wells, G. (1981). Learning through Interaction: the Study of Language Development. Cambridge: Cambridge University press.

\section{Copyrights}

Copyright for this article is retained by the author with first publication rights granted to the journal.

This is an open-access article distributed under the terms and conditions of the Creative Commons Attribution license (http://creativecommons.org/licenses/by/3.0/). 